\title{
A multicenter case registry study on medication-related osteonecrosis of the jaw in patients with advanced cancer
}

\author{
Morten Schiodt ${ }^{1}$ - Saroj Vadhan-Raj ${ }^{2}$ - Mark S. Chambers ${ }^{2} \cdot$ Ourania Nicolatou-Galitis $^{3} \cdot$ Constantinus Politis $^{4}$.

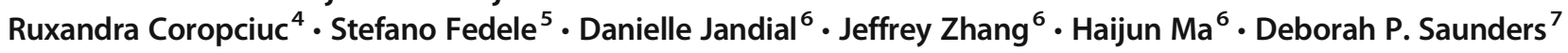

Received: 28 December 2016 / Accepted: 3 December 2017 / Published online: 23 December 2017

(C) The Author(s) 2017. This article is an open access publication

\begin{abstract}
Purpose This observational case registry study was designed to describe the natural history of cancer patients with medicationrelated osteonecrosis of the jaw (ONJ) and evaluate the ONJ resolution rate.

Methods Adults with a diagnosis of cancer and with a new diagnosis of ONJ were enrolled and evaluated by a dental specialist at baseline and every 3 months for 2 years and then every 6 months for 3 years until death, consent withdrawal, or loss to follow-up. The primary endpoint was the rate and time course of ONJ resolution. Secondary endpoints included frequency of incident ONJ risk factors, ONJ treatment patterns, and treatment patterns of antiresorptive agents for subsequent ONJ.

Results Overall, 327 patients were enrolled; 207 (63\%) were continuing on study at data cutoff. Up to 69\% of evaluable patients with ONJ had resolution or improvement during the study. ONJ resolution (AAOMS ONJ staging criteria) was observed in 114 patients (35\%); median (interquartile range) time from ONJ onset to resolution was 7.3 (4.5-11.4) months. Most patients (97\%) had received antiresorptive medication before ONJ development, 9 patients (3\%) had not; $68 \%$ had received zoledronic acid, $38 \%$ had received denosumab, and 10\% had received pamidronate (56\% had received bisphosphonates only, $18 \%$ had received denosumab only, and $21 \%$ had exposure to both).

Conclusions These results are consistent with those observed in clinical trials evaluating skeletal-related events in patients with advanced malignancy involving bone. Longer follow-up will provide further information on ONJ recurrence and resolution rates between medically and surgically managed patients.
\end{abstract}

Keywords Osteonecrosis of the jaw $\cdot$ Bisphosphonates $\cdot$ Denosumab $\cdot$ Risk factors $\cdot$ Outcomes $\cdot$ Treatment

Deborah P. Saunders

dsaunders@hsnsudbury.ca

1 Department of Oral and Maxillofacial Surgery, Rigshospitalet, Copenhagen University Hospital, Copenhagen, Denmark

2 MD Anderson Cancer Center, Houston, TX, USA

3 Clinic of Hospital Dentistry, Dental School, University of Athens, Athens, Greece

4 Department of Oral and Maxillofacial Surgery, University Hospitals Leuven, Leuven, Belgium

5 University College of London Eastman Dental Institute and National Institutes for Research Health, University College of London Hospitals Biomedical Research Center, London, UK

6 Amgen Inc, Thousand Oaks, CA, USA

7 Department of Dental Oncology, Health Sciences North, Northeast Cancer Centre, Northern Ontario School of Medicine, 41 Ramsey Lake Road, Sudbury, ON P3E 5J1, Canada

\section{Introduction}

Medication-related osteonecrosis of the jaw (ONJ) is an adverse drug reaction resulting in the progressive destruction of bone in the maxillofacial region [1-10]. Treatment of ONJ is typically challenging for physicians. Management depends on disease stage and can include conservative (e.g., oral rinses and antibiotics) or minimally invasive approaches (e.g., sequestrectomy, debridement), and major surgical intervention (e.g., resection) $[4,10,11]$, as well as discontinuation of the antiresorptive agent [10]. The goals of therapy for ONJ are to support continued oncologic therapy (largely because oncologic medications outweigh the risk, incidence, and/or evolution of ONJ lesions) and to control infection, pain, and progression of bone necrosis $[1,10]$. Historically, ONJ has been defined by the American Association of Oral and Maxillofacial Surgeons (AAOMS) as medication-induced 
exposition of bone in the maxillofacial region that does not heal within 8 weeks (in the absence of radiation of the jaw) [4, $10,12]$, with the revised 2014 definition including bone that can be probed through a fistula [10]. More recently, it has been suggested that the definition of ONJ should include nonexposed ONJ, which does not fulfill the current definition of ONJ [13-15]. There is a need to establish globally accepted criteria for nonexposed ONJ.

Antiresorptive bone-targeted agents such as nitrogenous bisphosphonates, which act on bone metabolism by binding and blocking the enzyme farnesyl diphosphate synthase in the HMG-CoA reductase pathway (i.e., the mevalonate pathway), and denosumab, the first receptor activator of nuclear factor-kappa $\beta$ ligand inhibitor to be approved by the US Food and Drug Administration, suppress bone turnover and are used to prevent bone complications (i.e., skeletal-related events [SREs]) in patients with solid tumors that have bone metastasis. However, these agents have been associated with a risk of developing ONJ [10-12, 16-23]. Time of exposure, number of treatments, duration of therapy, and cumulative dosage with antiresorptive therapies have been shown to increase the risk for developing ONJ [17, 24-27]. Development of ONJ may also occur more frequently in patients treated with intravenous bisphosphonates, compared with those given oral bisphosphonates (13- to 15-fold difference in risk) [28, 29]. Cofactors for increased risk of developing ONJ with antiresorptive therapies include concurrent inflammatory periodontal disease [16, 30-32], dental trauma (e.g., dental extraction, surgery to jawbones) [11, 12, 28, $30,31,33-37]$, and tobacco use [29, 34]. ONJ has also been reported in patients receiving antiangiogenic therapies such as bevacizumab [38, 39], sunitinib [40, 41], sorafenib [42], and cabozantinib [43].

Although the incidence of and risk factors associated with ONJ are well established, at present, there is limited information describing how ONJ is managed in routine clinical practice or resolution rates after such treatment. To this end, this observational case registry study was designed in line with STROBE guidance for epidemiology studies to describe the natural history of cancer patients with ONJ and evaluate the rate of ONJ resolution, particularly in comparison with rates previously observed in phase 3 clinical trials of SREs in patients with advanced cancer and bone metastasis receiving antiresorptive therapy $[21,22,25,44]$.

\section{Methods}

The ONJ case registry is a case-series prospective follow-up study of positively adjudicated ONJ cases. All patients provided informed consent.

\section{Patients}

Adults (aged $\geq 18$ years) with a diagnosis of cancer and with a new diagnosis of ONJ were identified by physicians at international cancer centers and underwent evaluation by a dental specialist to assess the suspected ONJ. Information derived from these examinations was then sent to an independent, external adjudication committee for diagnosis confirmation or rejection. Diagnosis was based on the AAOMS updated 2014 criteria for staging of medication-related ONJ (Table 1) and included patients with fistula tract but without frank bone exposure [10]. The external adjudication committee comprised experts in the field of ONJ diagnosis and treatment, and an oncologist and endocrinologist served as consultant experts as needed by adjudicators. Patients were considered eligible if they had newly diagnosed (defined as diagnosed within 6 months of existence) [10], positively adjudicated ONJ; had an Eastern Cooperative Oncology Group (ECOG) performance status $\leq 2$ with expected survival $\geq 3$ months; were willing to provide access to previous and future medical and dental information; and provided written informed consent. Patients were excluded if they had a history of radiation to the maxillofacial area, were unavailable for
Table 12014 American Association of Oral and Maxillofacial Surgeons staging of medication-related osteonecrosis of the jaw [10]

\begin{tabular}{cl}
\hline Stage & Description \\
\hline $0 \quad \begin{array}{l}\text { No clinical evidence of necrotic bone, but non-specific clinical findings, radiographic changes, and } \\
\text { symptoms }\end{array}$ \\
$1 \quad \begin{array}{l}\text { Exposed and necrotic bone, or fistulae that probe to bone, in patients who are asymptomatic and have no } \\
\text { evidence of infection }\end{array}$ \\
$\begin{array}{l}\text { Exposed and necrotic bone, or fistulae that probe to bone, associated with infection as evidenced by pain } \\
\text { and erythema in the region of the exposed bone with or without purulent drainage }\end{array}$ \\
$\begin{array}{l}\text { Exposed and necrotic bone, or fistulae that probe to bone, in patients with pain, infection, and one or } \\
\text { more of the following: exposed and necrotic bone extending beyond the region of alveolar bone (i.e., } \\
\text { inferior border and ramus in the mandible, maxillary sinus, and zygoma in the maxilla) resulting in } \\
\text { pathologic fracture, extra-oral fistula, oral antral/oral nasal communication, or osteolysis extending to } \\
\text { the inferior border of the mandible or sinus floor }\end{array}$ \\
\hline
\end{tabular}


protocol-required study visits, or had any disorder that would have compromised the ability to give written informed consent and/or to comply with study procedures. Patients were permitted to receive antiresorptive treatments such as bisphosphonates (oral or intravenous) or denosumab at enrollment and during the study. It is important to note that the study protocol initially aligned with the AAOMS 2009 criteria, which allowed for patients with ONJ and prior radiation to the maxillofacial area for palliative indications to be enrolled in the study [2]. However, the criteria were revised in the 2014 AAOMS position paper, and patients that had received any radiation to the maxillofacial region were subsequently excluded from participation in the study [10]. As a result, 14 patients $(4.3 \%)$ received radiation to the maxillofacial area for palliative indications in this study.

\section{Study design}

Study enrollment was planned to continue until approximately 300 patients with positively adjudicated ONJ were enrolled, including approximately 75 patients who were treated with denosumab as the only antiresorptive treatment. A sample size of 300 patients was expected to yield an ONJ resolution rate (defined as complete coverage of the exposed bone by mucosa in the absence of clinical symptoms) of $30 \%$ with a $95 \%$ CI of 25 to $35 \%$. The $30 \%$ predicted ONJ resolution rate was based on rates observed in prior clinical trials [21]. Patients with newly diagnosed ONJ were evaluated by a study dental specialist at baseline (i.e., enrollment) with follow-up assessments every 3 months for 2 years and then every 6 months for 3 years until death, withdrawal of consent, or loss to follow-up. The protocol allowed for standard-of-care ONJ treatment to be administered at the study sites, which was generally defined as the best course of treatment for each patient as determined by local dental and healthcare professionals and international or local treatment guidelines.

\section{Statistical analysis}

The primary endpoint of this study was the rate and time course of ONJ resolution (defined as complete coverage of exposed bone by mucosa, without the ability to probe necrotic bone, in the absence of clinical symptoms; radiological findings were not included as part of resolution assessment). Secondary endpoints included frequency of risk factors for incident ONJ, treatment patterns for ONJ, and treatment patterns of antiresorptive agents for subsequent ONJ. Data were summarized using descriptive statistics (i.e., mean and standard deviation for continuous variables and frequency for categorical variables).

\section{Results}

\section{Patients}

Between 1 October 2012 and 4 April 2016, 327 patients were enrolled from 64 study sites in North America and Europe. The data cutoff date for this analysis was 28 April 2016. Overall, 207 patients $(63 \%)$ were continuing on study at the data cutoff date; 120 patients $(37 \%)$ had discontinued the study. Reasons for study discontinuation included death $(n=$ 73), withdrawn consent $(n=17)$, loss to follow-up/noncompliance $(n=13)$, disease (cancer) progression $(n=8)$, administrative decision $(n=6)$, and study site closure $(n=3)$. The median (interquartile range [IQR]) length of follow-up after enrollment was 11.2 (6.3-17.3) months (mean [SD] was 12.6 (7.9) months). Median (IQR) time from cancer diagnosis to suspected onset of ONJ was 60.2 (30.8-116.4) months (mean [SD] was 83.3 [71.7] months).

The percentages of men and women in the study were similar (49 versus 51\%) and the median (IQR) age was 67 (59-74) years (Table 2). The mean (SD) age was 66.5 (10.8) years. Most patients had breast cancer $(37 \% ; n=120)$, prostate cancer $(25 \% ; n=81)$, or multiple myeloma $(22 \% ; n=72)$. The majority of patients had an ECOG performance status of 0 or $1(88 \% ; n=287)$. Of 228 patients with solid tumors, $91 \%$ had stage 4 disease, whereas patients with multiple myeloma most frequently had stage 3 disease $(37 \% ; n=27)$. Fifty-six percent of patients $(n=184)$ were current or former tobacco users.

\section{Medication use before development of ONJ}

Nearly all patients $(n=318 ; 97 \%)$ had received antiresorptive medication before development of ONJ; only 9 patients (3\%) had not received antiresorptive agents (Table 3). Of these 9 patients, 5 had exposure to a high-risk cancer medication such as antiangiogenic agents or corticosteroids (Table 3), 7 had prior tooth extractions, 7 had had no dental visits or cleanings in the 12 months prior to ONJ onset, 3 were current or former smokers, and 2 had medical comorbidities including diabetes mellitus. Two hundred twenty-one patients $(68 \%)$ had received zoledronic acid, 125 (38\%) had received denosumab, and $31(10 \%)$ had received pamidronate. Fifty-seven percent of patients $(n=186)$ had received bisphosphonates only, $19 \%$ $(n=63)$ had received denosumab only, and $21 \%$ of patients ( $n=69)$ had sequential exposure to both denosumab and bisphosphonates (in either order). Median (IQR) duration of antiresorptive medication before suspected ONJ onset was 27 (16-46) months; the mean (SD) duration was 34 (27) months. The median (IQR) durations of denosumab, bisphosphonates, or their combination before suspected ONJ onset were 15.7 (10.6-24.2) months for denosumab only, 26.2 (12.8-47.0) months for patients on bisphosphonates only, and 40.0 
Table 2 Baseline demographic and clinical characteristics

\begin{tabular}{lc}
\hline Characteristic & $\begin{array}{c}\text { Patients } \\
(N=327)\end{array}$ \\
\hline Median (IQR) age, years & $67(59-74)$ \\
Women, $n(\%)$ & $167(51)$ \\
ECOG performance status, $n(\%)$ & \\
0 & $159(49)$ \\
1 & $128(39)$ \\
2 & $38(12)$ \\
Median (IQR) months from cancer diagnosis to ONJ on- & $60(31-116)$ \\
set & \\
Type of cancer, $n$ (\%) & $120(37)$ \\
Breast & $81(25)$ \\
Prostate & $72(22)$ \\
Myeloma & $19(6)$ \\
Renal & $11(3)$ \\
Non-small-cell lung cancer & $4(1)$ \\
Thyroid & $16(5)$ \\
Other* & \\
Radiotherapy to the head and neck, $n(\%)$ & $311(95)$ \\
No & $16(5)$ \\
Yes & $2(1)$ \\
Curative intent & $14(4)$ \\
Palliative therapy & $184(56)$ \\
Previous or current tobacco user, $n(\%)$ & \\
\hline
\end{tabular}

ECOG Eastern Cooperative Oncology Group, IQR interquartile range, ONJ osteonecrosis of the jaw

*Includes colon, pancreatic, and sarcoma ( $n=2$ each) and cancer cardia adenocarcinoma, chest wall squamous cell carcinoma, giant cell tumor of bone, liver cancer, small-cell lung cancer, lymphoma, neuroendocrine tumor, ovarian cancer, melanoma, and testicular cancer ( $n=1$ each)

(27.6-60.8) months for patients who received denosumab and bisphosphonates. The mean (SD) durations were 18.4 (12.5) months for denosumab only, 35.6 (31.0) months for bisphosphonates only, and 46.4 (31.4) months for patients who received both.

In addition, other cancer medications that may have increased risk for ONJ development included angiogenics/ tyrosine kinase inhibitors (bevacizumab, sunitinib, sorafenib, or cabozantinib) in 37 patients (11\%), protein kinase inhibitors or other angiogenics in 46 patients (14\%), and corticosteroids/ immunosuppressants in 45 patients (14\%) (Table 3).

Compared to single agent therapy, patients exposed to both denosumab and bisphosphonates did not present with higher proportions of stage $3 \mathrm{ONJ}$ or severe symptoms (grade 3; National Cancer Institute Common Terminology Criteria for Adverse Events [NCI CTCAE], version 4.03). Furthermore, rates of associated local oral risk factors (such as tooth extractions) were similar in patients with combined exposure to denosumab and bisphosphonates and those exposed to single agent antiresorptives (Table 3). Following positive adjudication of ONJ and enrollment in the registry, approximately 10 to $20 \%$ of enrolled patients continued to use antiresorptive treatment at each post-enrollment time point; 65 patients $(20 \%)$ were still receiving antiresorptive therapy 3 months after enrollment in the study. Less than $10 \%$ of patients who were on study for $\geq 24$ months continued antiresorptive therapy.

Most patients $(n=246)$ discontinued treatment with antiresorptive medications after 3 months. Patients that discontinued antiresorptive treatment between baseline and 3 months had a higher percentage of stage 3 ONJ (11 versus $6 \%)$. Similarly, those patients $(n=65)$ who continued on antiresorptive medications after 3 months had a higher percentage of stage 1 asymptomatic ONJ at baseline (32 versus $24 \%$ ). Patients who continued on antiresorptive medications had a slightly lower percentage of ONJ resolution (28 versus $37 \%$ ). The median (IQR) time from ONJ onset to resolution for patients who continued antiresorptives was $6.0(4.0-10.3)$ months; for patients who discontinued, the time was 7.7 (4.9$11.5)$ months. The time to resolution of stage 1 asymptomatic ONJ was similar between patients that continued antiresorptive medication and those who discontinued treatment. However, the overall numbers may be too small to draw meaningful conclusions and these comparisons do not account for other confounders such as ongoing cancer therapies. Few patients $(n=3)$ were on antiresorptive treatment after 24 months. One patient was on zoledronic acid and two patients were on denosumab. One patient on denosumab had a giant cell tumor of bone where the therapy discontinuation risk outweighed the risk of ONJ. Before development of ONJ, there were a variety of anticancer and antiresorptive therapies administered to patients (Table 3).

\section{Patient ONJ status at baseline}

At baseline, most patients $(58 \% ; n=191)$ had stage 2 ONJ per the 2014 AAOMS guidelines (Table 4). The majority of patients had grade $2(64 \% ; n=208)$ or grade $3(6 \% ; n=19)$ symptomatic ONJ according to CTCAE version 4.03 classification of ONJ severity. Most patients had at least one ONJ lesion in the mandible (Table 4). Oral risk factors associated with ONJ included tooth extraction $(47 \% ; n=155)$, periodontal infection $(10 \% ; n=34)$, and denture trauma $(10 \% ; n=31)$; no ONJ local oral risk factors were identified in $31 \%$ of patients ( $n=100$; i.e., nonspecified ONJ).

\section{ONJ treatment patterns and outcomes}

The majority of patients included in the registry $(92 \% ; n=$ $300)$ were treated with medication for ONJ (Table 5): $80 \%$ $(n=263)$ received antibiotics and 59\% $(n=192)$ received oral rinses. Of the patients $(31 \% ; n=102)$ whose ONJ was surgically managed, 55 patients $(17 \%)$ were treated with minimally 
Table 3 Patient treatment before ONJ onset and stage at onset by antiresorptive regimen

Dmab only $(n=63) \quad$ BP only $(n=186) \quad$ Dmab + BP $(n=69) \quad$ No antiresorptives $(n=9) \quad$ All $(N=327)$

Cancer medications, $n(\%)$

Antineoplastic/chemotherapeutic agents

Hormonal agents/endocrine therapy

Other antineoplastic agents

Immunostimulants/immunomodulators

Other*

Antiresorptive medications, $n(\%)$

Antiangiogenics $\dagger$

Protein kinase inhibitors/other angiogenics

Corticosteroids/immunosuppressants

Duration of antiresorptive medication, months ${ }^{\ddagger}$

$<6$

$\geq 6$ to $<12$

$\geq 12$ to $<24$

$\geq 24$ to $<36$

$\geq 36$ to $<48$

$\geq 48$ to $<60$

$\geq 60$

Type of cancer, $n(\%)$

Breast

Prostate

Myeloma

Other

Stage at onset, $n(\%)$

Resolved

Stage 1

Stage 2

Stage 3

Unknown

Local oral risk factors ${ }^{\S}, n(\%)$

Tooth extraction

No identified factors

Periodontal infection

Denture trauma

Dental or oral surgery

Dental decay

Dental implant surgery

Other"

\begin{tabular}{|c|c|c|c|c|}
\hline $29(46.0)$ & 109 (58.6) & $38(55.1)$ & $5(55.6)$ & $181(55.4)$ \\
\hline 37 (58.7) & $76(40.9)$ & $49(71.0)$ & $3(33.3)$ & $165(50.5)$ \\
\hline $6(9.5)$ & 55 (29.6) & $3(4.3)$ & $4(44.4)$ & $68(20.8)$ \\
\hline 0 & $50(26.9)$ & $6(8.7)$ & $1(11.1)$ & $57(17.4)$ \\
\hline $3(4.8)$ & $1(0.5)$ & $5(7.2)$ & 0 & $9(2.8)$ \\
\hline $8(12.7)$ & $18(9.7)$ & $10(14.5)$ & $1(11.1)$ & 37 (11.3) \\
\hline $8(12.7)$ & $21(11.3)$ & $14(20.3)$ & $3(33.3)$ & $46(14.1)$ \\
\hline $1(1.6)$ & 37 (19.9) & $6(8.7)$ & $1(11.1)$ & 45 (13.8) \\
\hline $8(12.7)$ & $18(9.7)$ & $3(4.3)$ & NA & $23(7.0)$ \\
\hline $11(17.5)$ & $17(9.1)$ & $4(5.8)$ & & $32(9.8)$ \\
\hline 25 (39.7) & 48 (25.8) & $10(14.5)$ & & $83(25.4)$ \\
\hline $14(22.2)$ & $30(16.1)$ & $14(20.3)$ & & $58(17.7)$ \\
\hline $3(4.8)$ & $29(15.6)$ & $16(23.2)$ & & 48 (14.7) \\
\hline $1(1.6)$ & $15(8.1)$ & 8 (11.6) & & $24(7.3)$ \\
\hline $1(1.6)$ & 29 (15.6) & $14(20.3)$ & & $43(13.1)$ \\
\hline $22(34.9)$ & $71(38.2)$ & $24(34.8)$ & $3(33.3)$ & $120(36.7)$ \\
\hline 25 (39.7) & $26(14.0)$ & $29(42.0)$ & $1(11.1)$ & $81(24.8)$ \\
\hline 0 & 70 (37.6) & $1(1.4)$ & $1(11.1)$ & $72(22.0)$ \\
\hline $14(22.2)$ & $17(9.1)$ & 15 (21.7) & $4(44.4)$ & $50(15.3)$ \\
\hline $1(1.7)$ & $3(1.6)$ & $3(4.4)$ & 0 & $7(2.1)$ \\
\hline $13(20.6)$ & $50(26.9)$ & $18(26.1)$ & $5(55.6)$ & $86(26.3)$ \\
\hline $43(68.3)$ & $103(55.4)$ & $41(59.4)$ & $4(44.4)$ & $191(58.4)$ \\
\hline $6(9.5)$ & 23 (12.4) & $5(7.2)$ & 0 & $34(10.4)$ \\
\hline 0 & $7(3.8)$ & $2(2.9)$ & 0 & $9(2.8)$ \\
\hline $27(42.9)$ & $92(49.5)$ & $31(44.9)$ & $5(55.6)$ & $155(47.4)$ \\
\hline $23(36.5)$ & $60(32.3)$ & 15 (21.7) & $2(22.2)$ & $100(30.6)$ \\
\hline 7 (11.1) & $17(9.1)$ & $10(14.5)$ & 0 & $34(10.4)$ \\
\hline $6(9.5)$ & $15(8.1)$ & $9(13.0)$ & 1 (11.1) & $31(9.5)$ \\
\hline $5(7.9)$ & $12(6.5)$ & $7(10.1)$ & $1(11.1)$ & $25(7.6)$ \\
\hline 0 & $3(1.6)$ & $1(1.4)$ & 0 & $4(1.2)$ \\
\hline 0 & $1(0.5)$ & $1(1.4)$ & 0 & $2(0.6)$ \\
\hline $3(4.8)$ & $14(7.5)$ & $9(13.0)$ & 0 & $26(8.0)$ \\
\hline
\end{tabular}

$B P$ bisphosphonate, Dmab denosumab, $N A$ not applicable, $O N J$ osteonecrosis of the jaw

*Other medications include investigational products $(n=5)$

${ }^{\dagger}$ Antiangiogenic therapies include bevacizumab, sunitinib, sorafenib, and cabozantinib

$\star 16$ patients were not on antiresorptive agents before the onset of ONJ

${ }^{\S}$ Patients could be counted in more than one category

\| "Other" included bony exostosis, embedded tooth, exposed molar root mobile molar (right side), gingival inflammation, grossly decayed, injury after eating hard food, lingual torus, multiple decayed and unrestorable teeth mandibular component, mylohyoid region (anatomical predisposed region), injury, restant tooth roots potentially infecting area, self-expoliation, slight discomfort to the lateral border of the tongue, smoking, splint wear, the tooth has fallen by itself, undernourishment 
Table 4 Baseline ONJ status at enrollment

Overall $(N=327)$

$\begin{array}{lc}\text { AAOMS ONJ staging, } n(\%) & 86(26) \\ \text { Stage } 1 & 191(58) \\ \text { Stage } 2 & 34(10) \\ \text { Stage } 3 & 9(3) \\ \text { Unknown } & 7(2) \\ \text { Resolved* } & \\ \text { NCI CTCAE ONJ severity, } n(\%) & 85(26) \\ \text { Grade 1 (asymptomatic) } & 208(64) \\ \text { Grade 2 (symptomatic) } & 19(6) \\ \text { Grade 3 (severe symptoms) } & 8(2) \\ \text { Unknown } & 7(2) \\ \text { Resolved* } & \\ \text { Lesion location, }{ }^{\dagger} n \text { (\%) } & \\ \text { Mandible, teeth, and lateral jaw } & 231(71) \\ \text { Mandible, medial jaw } & 30(9) \\ \text { Maxilla, teeth, and lateral jaw } & 77(24) \\ \text { Maxilla, medial jaw } & 6(2) \\ \text { Maxilla, hard palate } & 2(1)\end{array}$

AAOMS American Association of Oral and Maxillofacial Surgeons, $N C I$ CTCAE National Cancer Institute Common Terminology Criteria for Adverse Events, $O N J$ osteonecrosis of the jaw

*Patients whose ONJ resolved between screening and enrollment

${ }^{\dagger}$ Patients could be counted in more than one category

Table 5 Summary of ONJ treatment

\begin{tabular}{lc}
\hline Treatment, $n(\%)$ & Patients $(N=327)$ \\
\hline Patients treated with medications & $300(92)$ \\
Antibiotics & $263(80)$ \\
Oral rinses* & $192(59)$ \\
Pain medications ${ }^{\dagger}$ & $27(8)$ \\
Antifungal/antimycotic & $8(2)$ \\
Other & $40(12)$ \\
Patients treated with surgical procedures & $102(31)$ \\
Sequestrectomy & $55(17)$ \\
Debridement & $32(10)$ \\
Resection with or without jaw reconstruction & $15(5)$ \\
Curettage & $13(4)$ \\
Tooth extraction (as treatment for ONJ) & $6(2)$ \\
Other & $8(2)$ \\
\hline
\end{tabular}

$O N J$ osteonecrosis of the jaw

* Oral rinse active ingredients by frequency of use were chlorhexidine, sodium hypochlorite, isobetadine, and urea hydrogen peroxide

${ }^{\dagger}$ Includes opioid and nonopioid pain medications

‡Includes mucosal reconstruction with buccinators flap, flap, selective milling flapless (without surgery), reoperation microanastomoses, radical left mandibulectomy, microvenous anastomoses recovery, osteotomy, fistula excision, replacement of fractual reconstruction plate (patients may have had multiple procedures), and removal of fractured lower left mandible invasive sequestrectomy and 32 patients (10\%) were treated with debridement. Fifteen patients $(5 \%)$ had resection with or without jaw reconstruction. Most (7/11) patients who underwent jaw resection without reconstruction had stage 2 ONJ lesions. All four patients who underwent jaw resection requiring reconstruction did so for progression to stage $3 \mathrm{ONJ}$ lesions. The majority of patients who required surgery also received antibiotics (96 patients, 94\%).

Antibiotic regimens and average treatment durations are shown in Table 6 . The most commonly used antibiotic class was extended-spectrum penicillins (212 courses). Doses of antibiotic therapy varied, although the doses were reflective of standard dose regimens. Two-hundred sixty-three $(80 \%)$ patients received 840 courses of antibiotics. The majority of patients required more than one course of therapy: $37 \%$ received a single course, $44 \%$ received $2-4$ courses, and $19 \%$ received $\geq 5$ courses. The average duration of antibiotic use was 28 days.

Last available ONJ status stratified by stage at baseline (AAOMS), type of antiresorptive exposure, and ONJ management strategy are listed in Table 7. Outcomes of ONJ according to AAOMS staging criteria, NCI CTCAE ONJ severity, ONJ lesion size grading (using guidelines provided by Weitzman et al., 2007 [45]), and clinical impression are summarized in Table 8 . In total, 55 to $69 \%$ of evaluable patients had resolution or improvement during the study (Table 8). A further 18 to $26 \%$ of patients were considered stable, and a smaller proportion of patients had ONJ progression (5-14\%; Table 8). ONJ resolution was observed in 114 patients $(35 \%)$, with the median (IQR) time from ONJ onset to resolution being 7.3 (4.5-11.4) months. Of these 114 patients, 43 (38\%) underwent surgical procedures and the remainder (71 patients [62\%]) were managed conservatively with medications only). Of the 34 patients with stage $3 \mathrm{ONJ}$ at baseline,

Table 6 Antibiotic regimens and duration of treatment

\begin{tabular}{rrl}
\hline Antibiotic class/category & Courses, $n(\%)$ & Average duration, $d$ \\
\hline Extended-spectrum penicillin & $212(25.2)$ & 48.8 \\
Amoxicillin-clavulanic acid & $175(20.8)$ & 26.6 \\
Tetracyclines & $119(14.2)$ & 10.4 \\
Clindamycin & $99(11.8)$ & 11.1 \\
Metronidazole & $96(11.4)$ & 17.4 \\
Penicillin VK & $50(6.0)$ & 40.7 \\
Cephalosporins & $21(2.5)$ & 27.7 \\
Fluoroquinolone & $20(2.4)$ & 63.3 \\
Macrolide & $19(2.3)$ & 27.3 \\
Ampicillin-sulbactam & $15(1.8)$ & 39.4 \\
Vancomycin & $12(1.4)$ & 17.3 \\
Aminoglycoside & $1(0.12)$ & 15.0 \\
Total & 840 & 28.2 \\
\hline Trimethoprim-sulfamethoxazole & $1(0.12)$ & 16.0 \\
\hline
\end{tabular}


Table 7 ONJ resolution by baseline staging and management

\begin{tabular}{|c|c|c|c|c|c|c|}
\hline \multirow[t]{2}{*}{ Characteristic } & \multicolumn{5}{|c|}{ Outcome, $n(\%)$} & \multirow{2}{*}{$\begin{array}{l}\text { Total } \\
(N=327)\end{array}$} \\
\hline & $\begin{array}{l}\text { Resolved } \\
(n=114)\end{array}$ & $\begin{array}{l}\text { Improved } \\
(n=50)\end{array}$ & $\begin{array}{l}\text { Progression } \\
(n=19)\end{array}$ & $\begin{array}{l}\text { Stable } \\
(n=83)\end{array}$ & $\begin{array}{l}\text { Not evaluable } \\
(n=61)\end{array}$ & \\
\hline \multicolumn{7}{|l|}{ Stage at enrollment* } \\
\hline Resolved $^{\dagger}$ & $5(1.5)$ & $2(0.6)$ & $0(0.0)$ & $0(0.0)$ & $0(0.0)$ & $7(2.1)$ \\
\hline 1 & $28(8.6)$ & $44(13.5)$ & $14(4.3)$ & $0(0.0)$ & $0(0.0)$ & $86(26.3)$ \\
\hline 2 & $67(20.5)$ & $45(13.8)$ & $74(22.6)$ & $5(1.5)$ & $0(0.0)$ & $191(58.4)$ \\
\hline 3 & $12(3.7)$ & $1(0.3)$ & $3(0.9)$ & $18(5.5)$ & $0(0.0)$ & $34(10.4)$ \\
\hline Not evaluable & $2(0.6)$ & $3(0.9)$ & $2(0.6)$ & $0(0.0)$ & $2(0.6)$ & $9(2.8)$ \\
\hline Total & $114(34.9)$ & $95(29.1)$ & $93(28.4)$ & $23(7.0)$ & $2(0.6)$ & $327(100.0)$ \\
\hline \multicolumn{7}{|l|}{ Antiresorptive therapy at baseline } \\
\hline Denosumab only & $26(41.3)$ & $10(15.9)$ & $1(1.6)$ & $14(22.2)$ & $12(19.0)$ & $63(19.3)$ \\
\hline Bisphosphonates only & $66(35.5)$ & $26(14.0)$ & $12(6.5)$ & $47(25.3)$ & $35(18.8)$ & $186(56.9)$ \\
\hline Denosumab plus bisphosphonate & $18(26.1)$ & $13(18.8)$ & $5(7.2)$ & $19(27.5)$ & $14(20.3)$ & $69(21.1)$ \\
\hline No antiresorptives & $4(44.4)$ & $1(11.1)$ & $1(11.1)$ & $3(33.3)$ & 0 & $9(2.8)$ \\
\hline \multicolumn{7}{|l|}{ Outcomes by management } \\
\hline Medications only & $63(31.0)$ & $29(14.3)$ & $10(4.9)$ & $50(24.6)$ & $51(25.1)$ & $203(62.1)$ \\
\hline Medication and surgery & $40(41.2)$ & $21(21.6)$ & $7(7.2)$ & $26(26.8)$ & $3(3.1)$ & $97(29.7)$ \\
\hline Surgery only & $3(60.0)$ & 0 & 0 & $1(20.0)$ & $1(20.0)$ & $5(1.5)$ \\
\hline No treatment & $8(36.4)$ & 0 & $2(9.1)$ & $6(27.3)$ & $6(27.3)$ & $22(6.7)$ \\
\hline
\end{tabular}

*2014 AAOMS staging

${ }^{\dagger}$ Patients whose ONJ resolved during the lag time between screening and enrollment. For all criteria, resolution was defined as complete coverage of the exposed bone by mucosa in the absence of clinical symptoms; improvement, progression, and stable were defined by comparing a patient's initial ONJ stage with that at the last available assessment

*Patients without any follow-up assessments after enrollment were coded as "not evaluable"

$12(35 \%)$ had ONJ resolution at the last post-baseline ONJ staging, comparable to the overall $\mathrm{ONJ}$ resolution rate.

\section{Discussion}

Most patients enrolled in this large international registry study had AAOMS stage 2 ONJ and CTCAE grade 2 (symptomatic) ONJ severity at baseline. The median time from cancer diagnosis to suspected ONJ onset was 60.2 months. Nearly all patients $(95 \%)$ with positively adjudicated ONJ in this registry had received antiresorptive medication before the onset of ONJ, including denosumab and/or bisphosphonates, with a median duration of treatment of 27.2 months. Of the 16 patients who did not receive antiresorptive medications, 4 received protein kinase inhibitors and 1 received immunosuppressants. Many patients had other local oral risk factors associated with the development of ONJ, with tooth extraction

Table 8 Summary of ONJ outcomes

\begin{tabular}{lccrc}
\hline Outcome, $n(\%)(N=327)$ & AAOMS ONJ staging & NCI CTCAE ONJ severity & Clinical impression & ONJ lesion size [45] \\
\hline Resolved* & $114(35)$ & $114(35)$ & $115(35)^{\dagger}$ & $114(35)$ \\
Improved & $50(15)$ & $59(18)$ & $52(16)$ & $32(10)$ \\
Progression & $19(6)$ & $16(5)$ & $45(14)$ & $36(11)$ \\
Stable & $83(25)$ & $77(24)$ & $59(18)$ & $84(26)$ \\
Not evaluable & $61(19)$ & $61(19)$ & $56(17)$ & $61(19)$ \\
\hline
\end{tabular}

AAOMS American Association of Oral and Maxillofacial Surgeons, NCI CTCAE Common Terminology Criteria for Adverse Events, ONJ osteonecrosis of the jaw

*For all criteria, resolution was defined as complete coverage of the exposed bone by mucosa in the absence of clinical symptoms; improvement, progression, and stable were defined by comparing a patient's initial ONJ stage with that at the last available assessment

${ }^{\dagger}$ One patient was considered to have ONJ that had resolved by clinical impression but not by stage, severity, and grade

*Patients without any follow-up assessments after enrollment were coded as "not evaluable" 
being the most frequent (47\%); however, $31 \%$ of patients had no notable ONJ risk factors (i.e., nonspecified ONJ). ONJ treatment among patients enrolled in the study was largely conservative, with most patients $(92 \%)$ receiving medications (e.g., antimicrobial oral rinses and/or antibiotics). Thirty-one percent of patients required limited surgical procedures to treat ONJ (e.g., debridement, sequestrectomy, curettage). ONJ resolution was observed in 35\% of patients (median follow-up time of 11 months) and overall, more than half of patients in the study had resolution or improvement of ONJ.

The definition of ONJ has changed in recent years. The original AAOMS definition centered on medication-induced exposure of bone; however, the revised classification includes bone that can be probed through a fistulous tract in the absence of exposed bone (i.e., nonexposed variant) [10]. These changes arose from studies that presented patients with fistulas or even patients without fistulas and no bone exposure [13-15]. When our study was initiated, the older definition was in use; however, the study was modified to include patients without bone exposure when the definition was updated.

Resolution of ONJ was observed in approximately one third of evaluable patients, with a median time to resolution of 7.3 months (time to resolution varied widely). If the lesions recurred $(n=14)$, they were not reported as resolved. Although this is an interim study and the full results will provide more information on the rate and time course for treatment outcomes, the findings were similar to those previously reported in patients with advanced cancer and bone metastases treated with bone-targeted agents. In previous studies, approximately 18 to $50 \%$ of patients treated with denosumab and 8 to $43 \%$ of patients treated with bisphosphonates had resolution of the ONJ event $[21,22$, 44]. Of the 114 patients whose ONJ lesions resolved, 43 (38\%) underwent surgical procedures and the remainder (71 patients [62\%]) were managed conservatively with medications only. Resolution of ONJ also varied by type of antiresorptive therapy at baseline; patients who received denosumab only had higher rates of resolution and lower rates of progression compared with those who received zoledronic acid only. The duration of antiresorptive therapy before ONJ also varied, with a shorter duration for denosumab compared with zoledronic acid. However, it should be noted that imbalances in baseline characteristics were observed; for example, there were more patients with prostate cancer who received denosumab only (40\%) than zoledronic acid only (14\%), and there were a greater number of patients with stage $3 \mathrm{ONJ}$ in the zoledronic acid cohort compared with denosumab (Table 3). It has been observed that patients with prostate cancer typically experience shorter time to ONJ compared to patients with breast cancer and longer time to resolution; these patients are also more likely to be older, have more comorbidities, and receive higher doses of corticosteroids compared with patients with breast cancer [46]. Because this trial was not designed with the expectation or statistical plan to account for differences in tumor types, such differences in baseline characteristics may confound final interpretation of the data. In fact, data from open-label extension studies have demonstrated no difference in the rates of ONJ between patients receiving denosumab or zoledronic acid [46].

The ONJ resolution rate in this registry study (35\%) is very similar to that reported in an integrated analysis of three SRE prevention studies in patients with bone metastases secondary to breast cancer, prostate cancer, or myeloma (36\%; median follow-up of 13 months) [25] and in an extension (up to 2 additional years) combining the breast and prostate cancer SRE prevention studies (36\%) [46]. The median cumulative denosumab exposure in the extensions was 43 months for breast cancer and 37 months for prostate cancer groups [47].

Many patients had risk factors for ONJ other than antiresorptive therapy exposure. These risk factors included tooth extraction/dental procedure and therapy with antiangiogenics or immunosuppressants, as well as dental/ periodontal infection and dental trauma. Thirty-one percent of patients had no identified local oral risk factors for ONJ. Reported rates of spontaneous ONJ range from 19 to $41 \%$ of studies with at least 100 patients exposed to bisphosphonates, which is consistent with our analysis [37, 48].

Notably, because even minor trauma, such as intubation or impression tray lesions, may lead to ONJ [37], it is possible that such factors were overlooked and thus not included in patients' charts or dental records. In the Copenhagen cohort of 149 patients, $64 \%$ were reported to have ONJ attributable to tooth extraction or dental trauma [37]; this is similar to the rate of $57 \%$ reported in the present study. It is also possible that other factors, such as viral infections [49], may have been overlooked and therefore not captured as possible risk factors.

At baseline, approximately two thirds of patients had stage $2 \mathrm{ONJ}$ and were symptomatic, and the majority of patients (95\%) received antiresorptive medication for a median of 27 months before ONJ onset. In previous studies, patients with an increased time of exposure to antiresorptive agents and those with a history of tooth extractions were also at greater risk of developing ONJ [17, 21, 22, 24, 31, 34, 44]. Furthermore, the duration of treatment with bone-targeted agents before the onset of ONJ in previous studies was similar to that seen in our study $[17,24,34]$. ONJ also appeared more frequently in the mandible than in the maxilla, which was consistent with previously reported findings $[16,17,24,30$, $34,50]$.

The key strength of this study is that this case registry report examined the effect of these therapies on ONJ in a substantial number of patients with advanced cancer and examined additional local oral and medication ONJ risk factors, as well as the treatment and management of ONJ and patient outcomes. Most previously published findings on medicationrelated ONJ have been based on small cohorts of patients or 
systematic reviews or integrated analyses of previously reported studies [4, 11, 17, 24, 25, 29, 33, 34].

This study had limitations. The study did not contain matched groups in which one group continued medication use and the other discontinued medication during the ONJ treatment period. Thus, it was not possible to evaluate patterns of resolution or recurrence after cessation or continuation of medication. Additionally, this study does not provide information about when to reinitiate medication after ONJ resolution. Finally, this study was observational in nature, and comparison between patients who received different antiresorptive treatments may be confounded by indication.

In summary, depending on the ONJ assessment tool used, up to $69 \%$ of evaluable patients had improvement or resolution of their ONJ event. These results are consistent with those observed in clinical trials evaluating SREs in patients with advanced malignancy involving bone. Longer follow-up will provide further information on important clinical questions such as recurrent $\mathrm{ONJ}$ and $\mathrm{ONJ}$ resolution rates between medically and surgically managed patients.

Acknowledgements The study was sponsored by Amgen Inc. Meghan Johnson and Rick Davis (Complete Healthcare Communications), whose work was sponsored by Amgen Inc., provided medical writing support.

Compliance with ethical standards All patients provided informed consent.

Conflict of interest DPS is a global advisor and investigator for Amgen and has received honoraria from Pfizer. SV-R received honoraria and research funding from Amgen. MSC and RC have no disclosures. ON$\mathrm{G}$ has received travel support from Novartis and travel support and honoraria from Amgen. CP has participated as an investigator in an Amgen trial. SF has received research funding and travel support and honoraria from Amgen and salary support from the National Institute for Health Research (NIHR). DJ, JZ, and HM are employees of and own stock in Amgen. MS has served as a consultant to and received honoraria from Amgen.

Ethics statement The study protocol was reviewed and approved by an independent ethics committee or institutional review board at each study center before enrollment of patients at that center.

Open Access This article is distributed under the terms of the Creative Commons Attribution-NonCommercial 4.0 International License (http:// creativecommons.org/licenses/by-nc/4.0/), which permits any noncommercial use, distribution, and reproduction in any medium, provided you give appropriate credit to the original author(s) and the source, provide a link to the Creative Commons license, and indicate if changes were made.

\section{References}

1. Rosella D, Papi P, Giardino R, Cicalini E, Piccoli L, Pompa G (2016) Medication-related osteonecrosis of the jaw: clinical and practical guidelines. J Int Soc Prev Community Dent 6(2):97104. https://doi.org/10.4103/2231-0762.178742
2. Ruggiero SL, Dodson TB, Assael LA, Landesberg R, Marx RE, Mehrotra B, American Association of Oral and Maxillofacial Surgeons (2009) American Association of Oral and Maxillofacial Surgeons position paper on bisphosphonate-related osteonecrosis of the jaws - 2009 update. J Oral Maxillofac Surg 67(5 Suppl):212. https://doi.org/10.1016/j.joms.2009.01.009

3. Khan A, Morrison A, Cheung A, Hashem W, Compston J (2016) Osteonecrosis of the jaw (ONJ): diagnosis and management in 2015. Osteoporos Int 27(3):853-859. https://doi.org/10.1007/ s00198-015-3335-3

4. Khan AA, Morrison A, Hanley DA, Felsenberg D, McCauley LK, O'Ryan F, Reid IR, Ruggiero SL, Taguchi A, Tetradis S, Watts NB, Brandi ML, Peters E, Guise T, Eastell R, Cheung AM, Morin SN, Masri B, Cooper C, Morgan SL, Obermayer-Pietsch B, Langdahl BL, Al Dabagh R, Davison KS, Kendler DL, Sandor GK, Josse RG, Bhandari M, El Rabbany M, Pierroz DD, Sulimani R, Saunders DP, Brown JP, Compston J, International Task Force on Osteonecrosis of the Jaw (2015) Diagnosis and management of osteonecrosis of the jaw: a systematic review and international consensus. J Bone Miner Res 30(1):3-23. https://doi.org/10.1002/jbmr. 2405

5. El-Rabbany M, Sgro A, Lam DK, Shah PS, Azarpazhooh A (2017) Effectiveness of treatments for medication-related osteonecrosis of the jaw: a systematic review and meta-analysis. J Am Dent Assoc

6. Kim KM, Rhee Y, Kwon YD, Kwon TG, Lee JK, Kim DY (2015) Medication related osteonecrosis of the jaw: 2015 position statement of the Korean Society for Bone and Mineral Research and the Korean Association of Oral and Maxillofacial Surgeons. J Bone Metab 22(4):151-165. https://doi.org/10.11005/jbm.2015.22.4.151

7. Svejda B, Muschitz C, Gruber R, Brandtner C, Svejda C, Gasser RW, Santler G, Dimai HP (2016) Position paper on medicationrelated osteonecrosis of the jaw (MRONJ). Wien Med Wochenschr 166(1-2):68-74. https://doi.org/10.1007/s10354-0160437-2

8. Yoneda T, Hagino H, Sugimoto T, Ohta H, Takahashi S, Soen S, Taguchi A, Nagata T, Urade M, Shibahara T, Toyosawa S (2017) Antiresorptive agent-related osteonecrosis of the jaw: position paper 2017 of the Japanese Allied Committee on Osteonecrosis of the Jaw. J Bone Miner Metab 35(1):6-19. https://doi.org/10.1007/ s00774-016-0810-7

9. Zhang X, Hamadeh IS, Song S, Katz J, Moreb JS, Langaee TY, Lesko LJ, Gong Y (2016) Osteonecrosis of the jaw in the United States Food and Drug Administration's Adverse Event Reporting System (FAERS). J Bone Miner Res 31(2):336-340. https://doi. org/10.1002/jbmr.2693

10. Ruggiero SL, Dodson TB, Fantasia J, Goodday R, Aghaloo T, Mehrotra B, O'Ryan F, American Association of Oral and Maxillofacial Surgeons (2014) American Association of Oral and Maxillofacial Surgeons position paper on medication-related osteonecrosis of the jaw-2014 update. J Oral Maxillofac Surg 72:1938-1956

11. Woo SB, Hellstein JW, Kalmar JR (2006) Systematic review: bisphosphonates and osteonecrosis of the jaws. Ann Intern Med 144(10):753-761. https://doi.org/10.7326/0003-4819-144-10200605160-00009

12. Khosla S, Burr D, Cauley J, Dempster DW, Ebeling PR, Felsenberg D, Gagel RF, Gilsanz V, Guise T, Koka S, McCauley LK, McGowan J, McKee MD, Mohla S, Pendrys DG, Raisz LG, Ruggiero SL, Shafer DM, Shum L, Silverman SL, Van Poznak CH, Watts N, Woo SB, Shane E (2007) Bisphosphonateassociated osteonecrosis of the jaw: report of a task force of the American Society for Bone and Mineral Research. J Bone Miner Res 22(10):1479-1491. https://doi.org/10.1359/jbmr.0707onj

13. Fedele S, Bedogni G, Scoletta M, Favia G, Colella G, Agrillo A, Bettini G, Di Fede O, Oteri G, Fusco V, Gabriele M, Ottolenghi L, Valsecchi S, Porter S, Fung PP, Saia G, Campisi G, Bedogni A 
(2015) Up to a quarter of patients with osteonecrosis of the jaw associated with antiresorptive agents remain undiagnosed. $\mathrm{Br} \mathbf{J}$ Oral Maxillofac Surg 53(1):13-17. https://doi.org/10.1016/j. bjoms.2014.09.001

14. Fedele S, Porter SR, D'Aiuto F, Aljohani S, Vescovi P, Manfredi M, Arduino PG, Broccoletti R, Musciotto A, Di Fede O, Lazarovici TS, Campisi G, Yarom N (2010) Nonexposed variant of bisphosphonate-associated osteonecrosis of the jaw: a case series. Am J Med 123(11):1060-1064. https://doi.org/10.1016/j.amjmed. 2010.04.033

15. Schiodt M, Reibel J, Oturai P, Kofod T (2014) Comparison of nonexposed and exposed bisphosphonate-induced osteonecrosis of the jaws: a retrospective analysis from the Copenhagen cohort and a proposal for an updated classification system. Oral Surg Oral Med Oral Pathol Oral Radiol 117(2):204-213. https://doi.org/10. 1016/j.0ooo.2013.10.010

16. Marx RE, Sawatari Y, Fortin M, Broumand V (2005) Bisphosphonate-induced exposed bone (osteonecrosis/ osteopetrosis) of the jaws: risk factors, recognition, prevention, and treatment. J Oral Maxillofac Surg 63(11):1567-1575. https:// doi.org/10.1016/j.joms.2005.07.010

17. Dimopoulos MA, Kastritis E, Anagnostopoulos A, Melakopoulos I, Gika D, Moulopoulos LA, Bamia C, Terpos E, Tsionos K, Bamias A (2006) Osteonecrosis of the jaw in patients with multiple myeloma treated with bisphosphonates: evidence of increased risk after treatment with zoledronic acid. Haematologica 91(7):968-971

18. Scagliotti GV, Hirsh V, Siena S, Henry DH, Woll PJ, Manegold C, Solal-Celigny P, Rodriguez G, Krzakowski M, Mehta ND, Lipton L, Garcia-Saenz JA, Pereira JR, Prabhash K, Ciuleanu TE, Kanarev V, Wang H, Balakumaran A, Jacobs I (2012) Overall survival improvement in patients with lung cancer and bone metastases treated with denosumab versus zoledronic acid: subgroup analysis from a randomized phase 3 study. J Thorac Oncol 7(12):1823-1829. https://doi.org/10.1097/JTO.0b013e31826aec2b

19. Papapoulos S, Chapurlat R, Libanati C, Brandi ML, Brown JP, Czerwinski E, Krieg MA, Man Z, Mellstrom D, Radominski SC, Reginster JY, Resch H, Roman Ivorra JA, Roux C, Vittinghoff E, Austin M, Daizadeh N, Bradley MN, Grauer A, Cummings SR, Bone HG (2012) Five years of denosumab exposure in women with postmenopausal osteoporosis: results from the first two years of the FREEDOM extension. J Bone Miner Res 27(3):694-701. https:// doi.org/10.1002/jbmr.1479

20. Qi WX, Tang LN, He AN, Yao Y, Shen Z (2014) Risk of osteonecrosis of the jaw in cancer patients receiving denosumab: a meta-analysis of seven randomized controlled trials. Int $\mathrm{J}$ Clin Oncol 19(2):403-410. https://doi.org/10.1007/s10147-013-0561-6

21. Henry DH, Costa L, Goldwasser F, Hirsh V, Hungria V, Prausova J, Scagliotti GV, Sleeboom H, Spencer A, Vadhan-Raj S, von Moos R, Willenbacher W, Woll PJ, Wang J, Jiang Q, Jun S, Dansey R, Yeh H (2011) Randomized, double-blind study of denosumab versus zoledronic acid in the treatment of bone metastases in patients with advanced cancer (excluding breast and prostate cancer) or multiple myeloma. J Clin Oncol 29(9):1125-1132. https://doi.org/ 10.1200/JCO.2010.31.3304

22. Fizazi K, Carducci M, Smith M, Damiao R, Brown J, Karsh L, Milecki P, Shore N, Rader M, Wang H, Jiang Q, Tadros S, Dansey R, Goessl C (2011) Denosumab versus zoledronic acid for treatment of bone metastases in men with castration-resistant prostate cancer: a randomised, double-blind study. Lancet 377(9768):813-822. https://doi.org/10.1016/S0140-6736(10) 62344-6

23. Lipton A, Balakumaran A (2012) Denosumab for the treatment of cancer therapy-induced bone loss and prevention of skeletal-related events in patients with solid tumors. Expert Rev Clin Pharmacol 5(4):359-371. https://doi.org/10.1586/ecp.12.35
24. Bamias A, Kastritis E, Bamia C, Moulopoulos LA, Melakopoulos I, Bozas G, Koutsoukou V, Gika D, Anagnostopoulos A, Papadimitriou C, Terpos E, Dimopoulos MA (2005) Osteonecrosis of the jaw in cancer after treatment with bisphosphonates: incidence and risk factors. J Clin Oncol 23(34): 8580-8587. https://doi.org/10.1200/JCO.2005.02.8670

25. Saad F, Brown JE, Van Poznak C, Ibrahim T, Stemmer SM, Stopeck AT, Diel IJ, Takahashi S, Shore N, Henry DH, Barrios CH, Facon T, Senecal F, Fizazi K, Zhou L, Daniels A, Carriere P, Dansey R (2012) Incidence, risk factors, and outcomes of osteonecrosis of the jaw: integrated analysis from three blinded active-controlled phase III trials in cancer patients with bone metastases. Ann Oncol 23(5):1341-1347. https://doi.org/10.1093/annonc/mdr435

26. Brenson JR, Stopeck AT (2016) Medication-related osteonecrosis of the jaw in patients with cancer. Available at: http://www. uptodate.com/contents/medication-related-osteonecrosis-of-thejaw-in-patients-with-cancer? topicKey $=$ O N C \% 2F96863\&elapsedTimeMs=1\&view=print\&displayedView=full. Accessed 2 Sep 2016

27. XGEVA® (denosumab). Full Prescribing Information, Amgen Inc., Thousand Oaks, CA, 2016. http://pi.amgen.com/ /media/amgen/ repositorysites/pi-amgen-com/xgeva/xgeva_pi.pdf

28. Yamazaki T, Yamori M, Ishizaki T, Asai K, Goto K, Takahashi K, Nakayama T, Bessho K (2012) Increased incidence of osteonecrosis of the jaw after tooth extraction in patients treated with bisphosphonates: a cohort study. Int J Oral Maxillofac Surg 41(11):1397-1403. https://doi.org/10.1016/j.ijom.2012.06.020

29. Wessel JH, Dodson TB, Zavras AI (2008) Zoledronate, smoking, and obesity are strong risk factors for osteonecrosis of the jaw: a case-control study. J Oral Maxillofac Surg 66(4):625-631. https:// doi.org/10.1016/j.joms.2007.11.032

30. Jacobsen C, Metzler P, Rossle M, Obwegeser J, Zemann W, Gratz KW (2013) Osteopathology induced by bisphosphonates and dental implants: clinical observations. Clin Oral Investig 17(1):167-175. https://doi.org/10.1007/s00784-012-0708-2

31. Vahtsevanos K, Kyrgidis A, Verrou E, Katodritou E, Triaridis S, Andreadis CG, Boukovinas I, Koloutsos GE, Teleioudis Z, Kitikidou K, Paraskevopoulos P, Zervas K, Antoniades K (2009) Longitudinal cohort study of risk factors in cancer patients of bisphosphonate-related osteonecrosis of the jaw. J Clin Oncol 27(32):5356-5362. https://doi.org/10.1200/JCO.2009.21.9584

32. Otto S, Troltzsch M, Jambrovic V, Panya S, Probst F, Ristow O, Ehrenfeld M, Pautke C (2015) Tooth extraction in patients receiving oral or intravenous bisphosphonate administration: a trigger for BRONJ development? J Craniomaxillofac Surg 43(6):847-854. https://doi.org/10.1016/j.jcms.2015.03.039

33. Giovannacci I, Meleti M, Manfredi M, Mortellaro C, Greco Lucchina A, Bonanini M, Vescovi P (2016) Medication-related osteonecrosis of the jaw around dental implants: implant surgerytriggered or implant presence-triggered osteonecrosis? J Craniofac Surg 27(3):697-701. https://doi.org/10.1097/SCS. 0000000000002564

34. Hoff AO, Toth BB, Altundag K, Johnson MM, Warneke CL, Hu M, Nooka A, Sayegh G, Guarneri V, Desrouleaux K, Cui J, Adamus A, Gagel RF, Hortobagyi GN (2008) Frequency and risk factors associated with osteonecrosis of the jaw in cancer patients treated with intravenous bisphosphonates. J Bone Miner Res 23(6):826-836. https://doi.org/10.1359/jbmr.080205

35. Pazianas M, Miller P, Blumentals WA, Bernal M, Kothawala P (2007) A review of the literature on osteonecrosis of the jaw in patients with osteoporosis treated with oral bisphosphonates: prevalence, risk factors, and clinical characteristics. Clin Ther 29(8): 1548-1558. https://doi.org/10.1016/j.clinthera.2007.08.008

36. Lopez-Cedrun JL, Sanroman JF, Garcia A, Penarrocha M, Feijoo JF, Limeres J, Diz P (2013) Oral bisphosphonate-related osteonecrosis of the jaws in dental implant patients: a case series. 
Br J Oral Maxillofac Surg 51(8):874-879. https://doi.org/10.1016/j. bjoms.2013.06.011

37. Yazdi PM, Schiodt M (2015) Dentoalveolar trauma and minor trauma as precipitating factors for medication-related osteonecrosis of the jaw (ONJ): a retrospective study of 149 consecutive patients from the Copenhagen ONJ cohort. Oral Surg Oral Med Oral Pathol Oral Radiol 119(4):416-422. https://doi.org/10.1016/j. oooo.2014.12.024

38. Serra E, Paolantonio M, Spoto G, Mastrangelo F, Tetè S, Dolci M (2009) Bevacizumab-related osteneocrosis of the jaw. Int J Immunopathol Pharmacol 22(4):1121-1123. https://doi.org/10. 1177/039463200902200429

39. Pakosch D, Papadimas D, Munding J, Kawa D, Kriwalsky MS (2013) Osteonecrosis of the mandible due to anti-angiogenic agent, bevacizumab. Oral Maxillofac Surg 17(4):303-306. https://doi.org/ 10.1007/s10006-012-0379-9

40. Nicolatou-Galitis O, Migkou M, Psyrri A, Bamias A, Pectasides D, Economopoulos T, Raber-Durlacher JE, Dimitriadis G, Dimopoulos MA (2012) Gingival bleeding and jaw bone necrosis in patients with metastatic renal cell carcinoma receiving sunitinib: report of 2 cases with clinical implications. Oral Surg Oral Med Oral Pathol Oral Radiol 113(2):234-238. https://doi.org/10.1016/j. tripleo.2011.08.024

41. Koch FP, Walter C, Hansen T, Jager E, Wagner W (2011) Osteonecrosis of the jaw related to sunitinib. Oral Maxillofac Surg 15(1):63-66. https://doi.org/10.1007/s10006-010-0224-y

42. Garuti F, Camelli V, Spinardi L, Bucci L, Trevisani F (2016) Osteonecrosis of the jaw during sorafenib therapy for hepatocellular carcinoma. Tumori 0

43. Marino R, Orlandi F, Arecco F, Gandolfo S, Pentenero M (2015) Osteonecrosis of the jaw in a patient receiving cabozantinib. Aust Dent J 60(4):528-531. https://doi.org/10.1111/adj.12254

44. Stopeck AT, Lipton A, Body JJ, Steger GG, Tonkin K, de Boer RH, Lichinitser M, Fujiwara Y, Yardley DA, Viniegra M, Fan M, Jiang
Q, Dansey R, Jun S, Braun A (2010) Denosumab compared with zoledronic acid for the treatment of bone metastases in patients with advanced breast cancer: a randomized, double-blind study. J Clin Oncol 28(35):5132-5139. https://doi.org/10.1200/JCO.2010.29. 7101

45. Weitzman R, Sauter N, Eriksen EF, Tarassoff PG, Lacerna LV, Dias R, Altmeyer A, Csermak-Renner K, McGrath L, Lantwicki L, Hohneker JA (2007) Critical review: updated recommendations for the prevention, diagnosis, and treatment of osteonecrosis of the jaw in cancer patients-May 2006. Crit Rev Oncol Hematol 62(2):148-152. https://doi.org/10.1016/j.critrevonc.2006.12.005

46. Stopeck AT, Fizazi K, Body J-J, Brown JE, Carducci M, Diel I, Fujiwara Y, Martín M, Paterson A, Tonkin K, Shore N, Sieber P, Kueppers F, Karsh L, Yardley D, Wang H, Maniar T, Arellano J, Braun A (2016) Safety of long-term denosumab therapy: results from the open label extension phase of two phase 3 studies in patients with metastatic breast and prostate cancer. Support Care Cancer 24(1):447-455. https://doi.org/10.1007/s00520-015-2904-5

47. Stopeck AT, Warner DJ (2016) Response to letter to the editorssafety of long-term denosumab therapy. Support Care Cancer 1-3

48. Pichardo SE, van Merkesteyn JP (2013) Bisphosphonate related osteonecrosis of the jaws: spontaneous or dental origin? Oral Surg Oral Med Oral Pathol Oral Radiol 116(3):287-292. https://doi.org/ 10.1016/j.00oo.2013.05.005

49. Almazrooa SA, Woo SB (2009) Bisphosphonate and nonbisphosphonate-associated osteonecrosis of the jaw: a review. J Am Dent Assoc 140(7):864-875. https://doi.org/10.14219/jada. archive.2009.0280

50. Kwon TG, Lee CO, Park JW, Choi SY, Rijal G, Shin HI (2014) Osteonecrosis associated with dental implants in patients undergoing bisphosphonate treatment. Clin Oral Implants Res 25(5):632640. https://doi.org/10.1111/clr.12088 